\title{
Synthesis and Characterization of Iron Oxide Nanoparticles and Applications in the Removal of Heavy Metals from Industrial Wastewater
}

\author{
Zuolian Cheng, ${ }^{1}$ Annie Lai Kuan Tan, ${ }^{1}$ Yong Tao, ${ }^{2}$ Dan Shan, ${ }^{2}$ \\ Kok Eng Ting, ${ }^{1}$ and Xi Jiang Yin ${ }^{2}$ \\ ${ }^{1}$ School of Chemical \& Life Sciences, Singapore Polytechnic, 500 Dover Road, Singapore 139651 \\ ${ }^{2}$ Advanced Material Technology Centre, Singapore Polytechnic, 500 Dover Road, Singapore 139651 \\ Correspondence should be addressed to Zuolian Cheng, cheng@sp.edu.sg
}

Received 16 January 2012; Accepted 17 February 2012

Academic Editor: Stéphane Jobic

Copyright (๑) 2012 Zuolian Cheng et al. This is an open access article distributed under the Creative Commons Attribution License, which permits unrestricted use, distribution, and reproduction in any medium, provided the original work is properly cited.

This study investigated the applicability of maghemite $\left(\gamma-\mathrm{Fe}_{2} \mathrm{O}_{3}\right)$ nanoparticles for the selective removal of toxic heavy metals from electroplating wastewater. The maghemite nanoparticles of $60 \mathrm{~nm}$ were synthesized using a coprecipitation method and characterized by X-ray diffraction (XRD) and scanning electron microscopy (SEM) equipped with energy dispersive X-ray spectroscopy (EDX). Batch experiments were carried out for the removal of $\mathrm{Pb}^{2+}$ ions from aqueous solutions by maghemite nanoparticles. The effects of contact time, initial concentration of $\mathrm{Pb}^{2+}$ ions, solution $\mathrm{pH}$, and salinity on the amount of $\mathrm{Pb}^{2+}$ removed were investigated. The adsorption process was found to be highly $\mathrm{pH}$ dependent, which made the nanoparticles selectively adsorb this metal from wastewater. The adsorption of $\mathrm{Pb}^{2+}$ reached equilibrium rapidly within 15 min and the adsorption data were well fitted with the Langmuir isotherm.

\section{Introduction}

With heavy metal pollution becoming one of the most serious environmental problems, various methods for heavy metal removal from wastewater have been extensively studied during the past decades, such as chemical precipitation, electrochemical techniques, membrane filtration, ion exchange, and adsorption [1]. To date, considerable research attention has been paid to the removal of heavy metals from contaminated water via adsorption process. In theory, the adsorption process can offer flexibility in design and operation and in many cases will produce high-quality treated effluent. In addition, as the adsorption is sometimes reversible and adsorbent can be regenerated by suitable desorption process, various types of adsorbents have found application in the removal of heavy metals, including activated carbon $[2,3]$, carbon nanotubes [4-6], polymeric adsorbents [7], metal oxides [8], and bioadsorbents [9-12]. Among these adsorbents, iron-based magnetic nanomaterials have distinguished themselves by their unique properties, such as larger surface area-volume ratio, diminished consumption of chemicals, and no secondary pollutant. However, with another special property of this kind magnetic materials are realized and utilized in the context of environmental remediation. More and more magnetic separation has been combined with adsorption for the removal of heavy metals from contaminated water at laboratory scales [13-15]. Especially in industries, magnetic separation is desirable because it can overcome many drawbacks occurring in the membrane filtration, centrifugation, or gravitational separation and is easy to achieve a given level of separation just via external magnetic field.

Iron oxides exit in many forms in nature, with magnetite $\left(\mathrm{Fe}_{3} \mathrm{O}_{4}\right)$, hematite $\left(\alpha-\mathrm{Fe}_{2} \mathrm{O}_{3}\right)$ and maghemite $\left(\gamma\right.$ - $\left.\mathrm{Fe}_{2} \mathrm{O}_{3}\right)$, being most probably common and important technologically [16]. It has been reported that surface effects have a strong influence on the magnetic properties of iron oxide nanoparticles [17]. As the surface area of iron-oxide-based magnetic materials decreased, their responses to external magnetic field decreased, making it difficult to recover the adsorbents 
after treatment has been completed [14]. On the other hand, it has also been noted that the adsorption capacities of adsorbents rely largely on the available surface areas, and the increase of the surface area is normally obtained by the decrease of the particle size of adsorbents. As a result, there is a need to synthesize such absorbents with proper particles sizes for the removal of heavy metals from industrial wastewater.

Up to now, there are several methods that can be used to synthesize iron-oxide-based nanomaterials. These methods include hydrothermal synthesis [18, 19], thermal decomposition [20, 21], co-precipitation [22, 23], sol-gel method [15], and colloidal chemistry method [24]. Among these synthesis methods, coprecipitation has proven to be the most promising method for the production of nanomaterials as the procedure is relatively simple and the particles can be obtained with controlled particle size.

The specific objective of the present study was (1) to synthesize $\gamma-\mathrm{Fe}_{2} \mathrm{O}_{3}$ nanoparticles using a modified method, which involved urea as a uniformity precipitation reagent, (2) to characterize $\gamma$ - $\mathrm{Fe}_{2} \mathrm{O}_{3}$ nanoparticles synthesized using different kinds of analytical instruments, and (3) to evaluate synthesized $\gamma-\mathrm{Fe}_{2} \mathrm{O}_{3}$ nanoparticles as adsorbents to remove heavy metals such as $\mathrm{Pb}^{2+}$ from industrial wastewater.

\section{Experimental}

2.1. Preparation and Characterization of $\gamma-\mathrm{Fe}_{2} \mathrm{O}_{3}$ Nanoparticles. The synthesis of $\gamma-\mathrm{Fe}_{2} \mathrm{O}_{3}$ nanoparticles involves the following steps: (1) a designated molar ratio of iron chloride and urea was dissolved in deionized water; (2) the mixture was continuously stirred for $45 \mathrm{~min}$ at $90^{\circ} \mathrm{C}$ in a water bath before it was cooled to room temperature; (3) the produced precipitation was centrifuged and washed by deionized water and followed by ethanol; (4) after being dried at $75^{\circ} \mathrm{C}$ for 4 hours, the collected powder was slowly calcined to $650^{\circ} \mathrm{C}$ in air and dwelt for 2 hours. The resultant product of $\gamma-\mathrm{Fe}_{2} \mathrm{O}_{3}$ nanoparticles was obtained for subsequent characterization.

A scanning electron microscope (SEM, JEOL JEM2010, Japan) was used to characterize the structure properties of the synthesized materials. The element composition of the synthesized materials was identified by an energy dispersive X-ray spectroscopy system (EDX) coupled to the SEM. The crystallization phase analysis was executed by a powder X-ray diffraction (XRD) (Philips PW-1830, Netherlands). Magnetization measurement was carried out with a vibration sample magnetometer (VSM) at room temperature.

2.2. Removal of Heavy Metals from Wastewater. A stock solution containing $\mathrm{Pb}^{2+}$ was prepared by dissolving a known quantity of lead nitrate $\left(\mathrm{Pb}\left(\mathrm{NO}_{3}\right)_{2}\right)$ in deionized water. Batch adsorption studies were performed by mixing $0.5 \mathrm{~g}$ of $\gamma-\mathrm{Fe}_{2} \mathrm{O}_{3}$ with $50 \mathrm{~mL}$ of solutions of varying $\mathrm{Pb}^{2+}$ concentrations $(50,100$, and $150 \mathrm{mg} / \mathrm{L})$ in $100 \mathrm{~mL}$ glass vials. The adsorption on $\gamma-\mathrm{Fe}_{2} \mathrm{O}_{3}$ was first studied at $\mathrm{pH}$ values of 2.5 to 6.5 to investigate the effects of $\mathrm{pH}$ values on the $\mathrm{Pb}^{2+}$ adsorption. $0.1 \mathrm{M} \mathrm{HCl}$ and $0.1 \mathrm{M} \mathrm{NaOH}$ solutions were used to adjust the $\mathrm{pH}$ values of water samples. The $\mathrm{pH}$ values of water samples were stable over the the experiment period. All the adsorption experiments were carried out at a room temperature of $22 \pm 2{ }^{\circ} \mathrm{C}$ and were performed in triplicate. The total aqueous concentrations of $\mathrm{Pb}^{2+}$ were measured using an inductively coupled plasma-optical emission spectrometer (ICP-OES, Thermo, icap 6000). Sample dilution was conducted before the ICP-OES measurement, where necessary.

\section{Results and Discussion}

3.1. Synthesis and Characterization of $\gamma-\mathrm{Fe}_{2} \mathrm{O}_{3}$. The crystalline grain size is mainly determined by both the formation energy of growth unit and the lattice energy, besides different synthesis conditions. In the present study, $\mathrm{Fe}_{2} \mathrm{O}_{3}$ nanoparticles were synthesized by varying $\mathrm{pH}$ values, ageing time, the mass ratio of $\mathrm{FeCl}_{3}$ and urea, and so forth. Figure 1(a) shows an SEM image of the synthesized $\gamma-\mathrm{Fe}_{2} \mathrm{O}_{3}$, confirming that the particles obtained were indeed in the nanometer range. Upon ageing for different durations, it was observed that the grain size increased with increasing ageing time. The smallest grain size $(63.20 \pm 0.928 \mathrm{~nm})$ was obtained after ageing for 45 minutes. In addition, strong peaks for $\mathrm{Fe}$ and $\mathrm{O}$ can be observed in the spectrum illustrated in Figure 1(b) for particles after ageing time of $45 \mathrm{~min}$. The insert of Figure 1(b) reveals that the $\mathrm{O} / \mathrm{Fe}$ atomic ratio of the $\gamma-\mathrm{Fe}_{2} \mathrm{O}_{3}$ analyzed was 1.56 , which was relatively consistent with the theoretical $\mathrm{O} / \mathrm{Fe}$ atomic ratio of 1.50 .

The magnetization with respect to applied field was recorded at room temperature. The hysteresis loop, shown in Figure 2, suggested a weak magnetic nature of the samples with little hysteresis. The weak magnetism might be caused by the presence of $\alpha-\mathrm{Fe}_{2} \mathrm{O}_{3}$ as detected by XRD. From Figure 2, the $\mathrm{M}_{\mathrm{S}}$ was calculated to be $0.025 \mathrm{emu} / \mathrm{g}$ and the $\mathrm{H}_{\mathrm{C}}$ to be $1250 \mathrm{Oe}$.

Figure 3 shows the results of XRD analysis for the synthesized nanoparticles that were obtained with different initial concentrations of $\mathrm{FeCl}_{3}$. It indicates that the particles consist of $\gamma-\mathrm{Fe}_{2} \mathrm{O}_{3}$ (peaks denoted by $*$ ) and $\alpha-\mathrm{Fe}_{2} \mathrm{O}_{3}$ (peaks denoted by \#). It also indicates that a concentration of $0.02 \mathrm{M}$ of $\mathrm{FeCl}_{3}$ resulted in the particles with the smallest $\mathrm{Z}$-average diameter. Therefore, $0.02 \mathrm{M}$ was the optimized concentration for $\mathrm{FeCl}_{3}$.

\subsection{Effect of Adsorption Time and Initial Concentration.} The adsorption of $\mathrm{Pb}^{2+}$ onto $\gamma-\mathrm{Fe}_{2} \mathrm{O}_{3}$ nanoparticles was monitored for $120 \mathrm{~min}$. The initial $\mathrm{Pb}^{2+}$ concentrations were 50,100 , and $150 \mathrm{mg} / \mathrm{L}$, respectively. The initial $\mathrm{pH}$ value of water samples was 5.5, and the solution temperature was $22 \pm 2{ }^{\circ} \mathrm{C}$. As seen in Figure $4, \mathrm{~Pb}^{2+}$ ions were adsorbed onto $\gamma-\mathrm{Fe}_{2} \mathrm{O}_{3}$ nanoparticles rapidly, and equilibrium was established within 30 minutes. This could be due to the small size of $\gamma$ - $\mathrm{Fe}_{2} \mathrm{O}_{3}$ nanoparticles, which was favorable for the diffusion of $\mathrm{Pb}^{2+}$ ions from bulk solution onto the active sites of the solid surface. External adsorption dominated and no pore diffusion was observed to slow down the adsorption rate. Despite the short equilibrium time, a 24-h contact time was adopted for the subsequent experiment to 


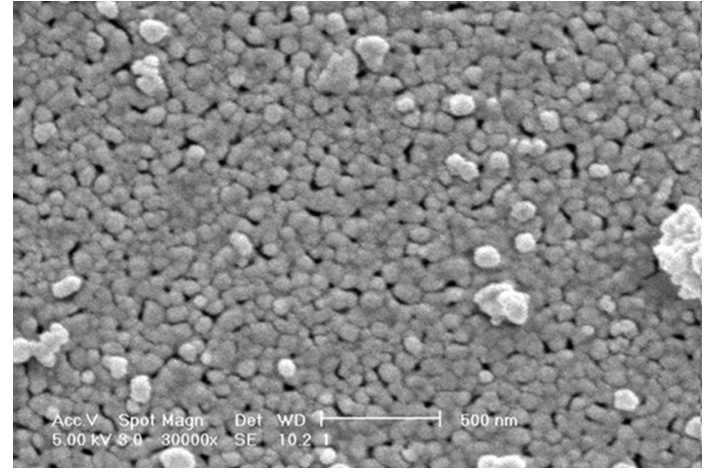

(a)

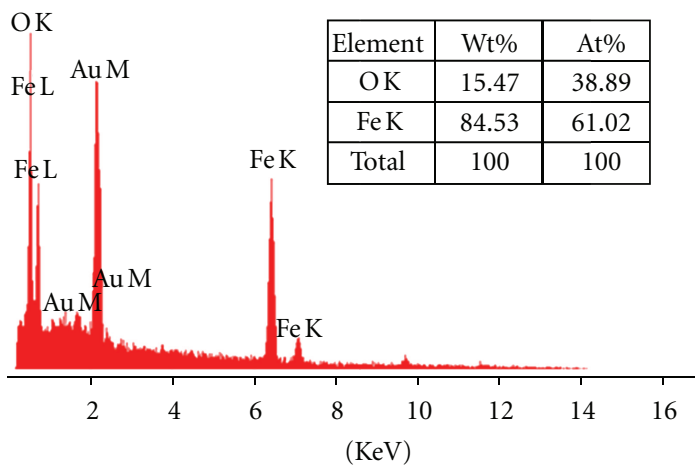

(b)

FIGURE 1: SEM image and EDX spectrum for $\gamma-\mathrm{Fe}_{2} \mathrm{O}_{3}$ nanoparticles.

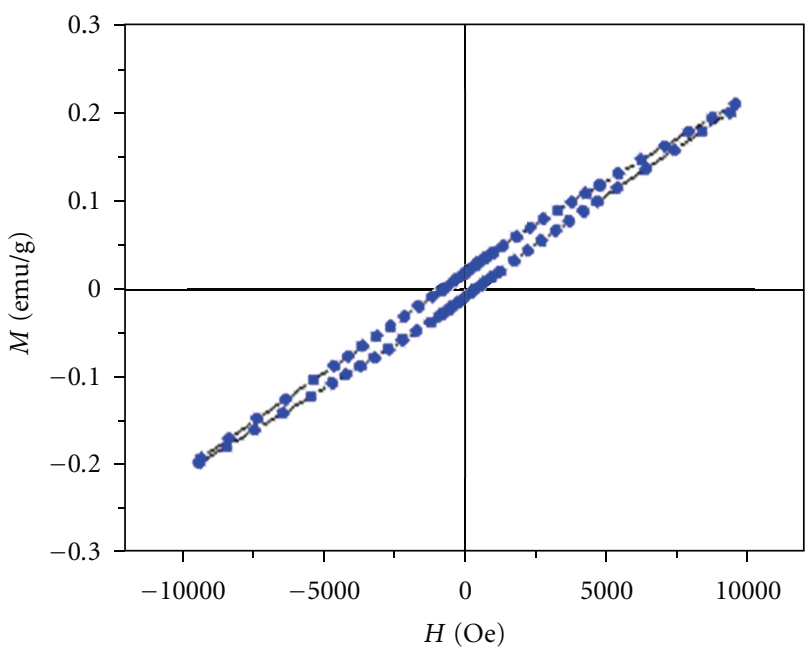

Figure 2: VSM measurements for $\gamma-\mathrm{Fe}_{2} \mathrm{O}_{3}$ nanoparticles. ensure that adsorption equilibrium was achieved. The short equilibrium time was in agreement with that reported by other researchers for the adsorption of other metal ions onto iron oxide nanoparticles [25-27]. This is in contrast to other conventional porous adsorbents in which adsorption occurs through pore diffusion steps, which in turn slow down the adsorption rate. The $\gamma-\mathrm{Fe}_{2} \mathrm{O}_{3}$ nanoparticles are nonporous adsorbents, as confirmed by the surface area and porosity measurements, where only external adsorption occurred. This type of adsorption mass transfer requires less time to reach the equilibrium [28]. This result is promising as equilibrium time plays a major role in economic viability for wastewater treatment plant. Furthermore, as shown in Figure 4, the amount adsorbed of $\mathrm{Pb}^{2+}$ increased with the increase in the initial concentration of $\mathrm{Pb}^{2+}$ in water samples. This can be attributed to the increase in the ion occupancy number, which favors the adsorption process.

3.3. Effect of $p H$. It is well known that $\mathrm{pH}$ is one of the most important factors that affect the adsorption process of heavy metals in water samples. The experiments were carried out

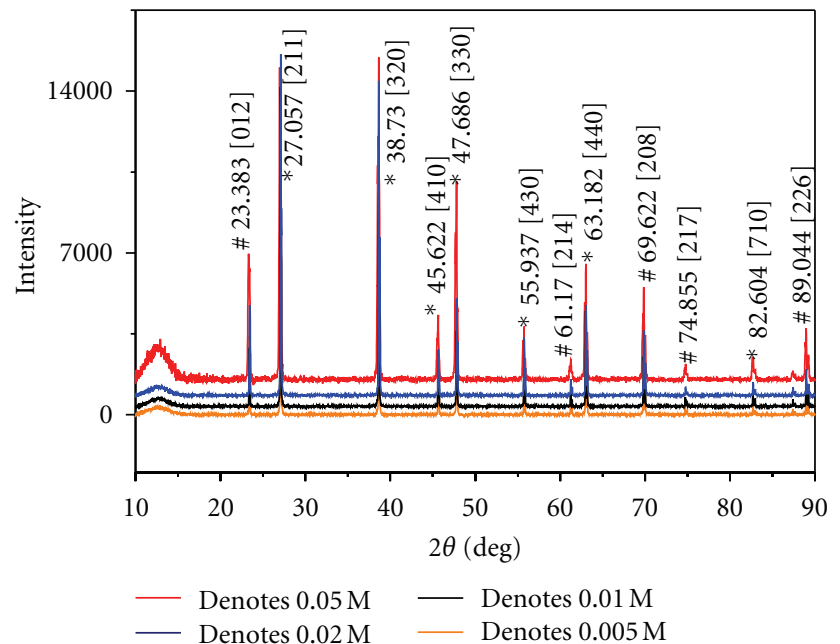

FIGURE 3: XRD patterns of synthesized $\gamma-\mathrm{Fe}_{2} \mathrm{O}_{3}$ nanoparticles with different concentrations of $\mathrm{FeCl}_{3}$.

to find the optimum $\mathrm{pH}$ on the adsorption of $\mathrm{Pb}^{2+}$ ions onto $\gamma-\mathrm{Fe}_{2} \mathrm{O}_{3}$ nanoparticles using different initial $\mathrm{pH}$ values of 2.5 to 6.5 . The experimental $\mathrm{pH}$ values of up to 6.5 were chosen as precipitation of lead hydroxide would occur at $\mathrm{pH}$ values equal to or higher than 7.0, even though other variables such as the amount of nanoparticles were fixed [29]. Therefore, it was not feasible to carry out the adsorption experiments for $\mathrm{Pb}^{2+}$ at $\mathrm{pH}>6.5$ without introducing some uncertainties to the results. Figure 5 shows the effects of $\mathrm{pH}$ on the adsorption of $\mathrm{Pb}^{2+}$. As observed in the graph, the removal efficiency of $\mathrm{Pb}^{2+}$ ions from watersamples by the $\gamma-\mathrm{Fe}_{2} \mathrm{O}_{3}$ nanoparticles was clearly $\mathrm{pH}$ dependent and the highest adsorption efficiency was obtained at $\mathrm{pH} \geq 5$.5. Lee et al. also observed a similar $\mathrm{pH}$ effect for the adsorption of $\mathrm{Pb}^{2+}$ onto bulk iron oxides in water samples [30]. It indicated that a water sample with a higher $\mathrm{pH}$ value was favorable for the deprotonation of sorbent surface [31, 32]. Increased deprotonation could result in the increase of negatively charged sites, which enhanced the attractive forces between the sorbent surface and the $\mathrm{Pb}^{2+}$ ions. Therefore, it will result 


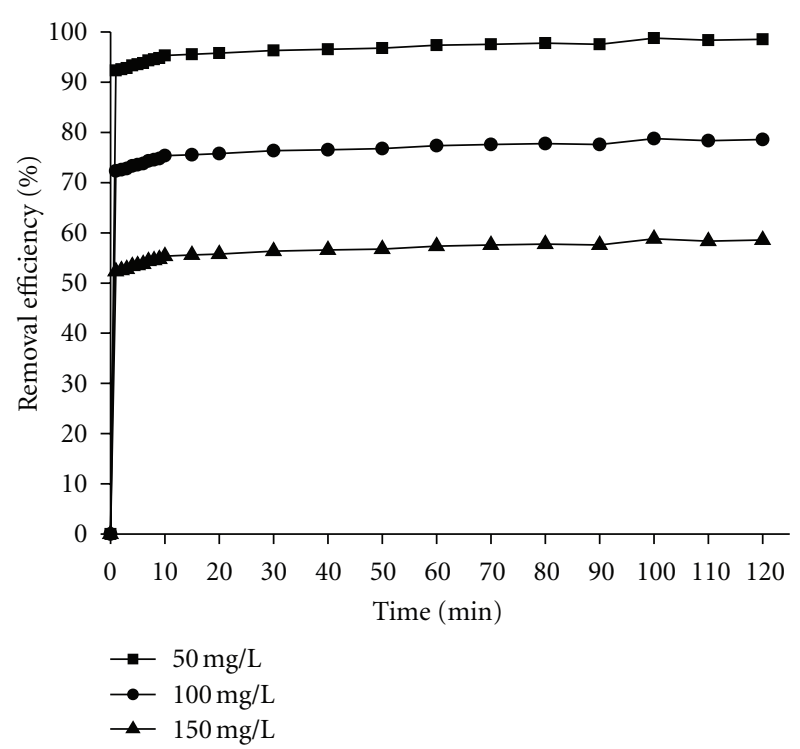

Figure 4: Effect of contact time on the removal of $\mathrm{Pb}^{2+}$ at different initial concentrations. Adsorbent dose: $10 \mathrm{~g} / \mathrm{L}$, shaking rate: $200 \mathrm{rpm}, \mathrm{pH}: 5.5, T: 22 \pm 2^{\circ} \mathrm{C}$.

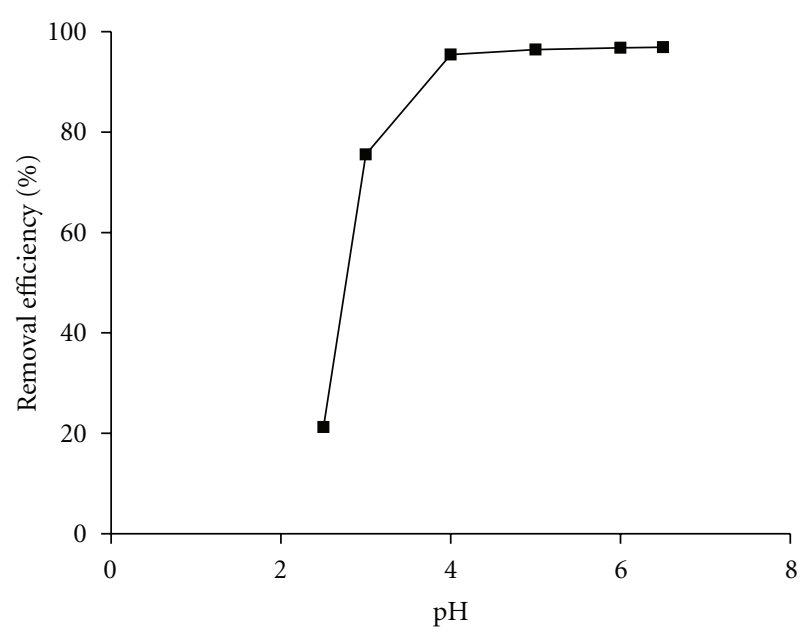

FIGURE 5: Effect of $\mathrm{pH}$ on $\mathrm{Pb}^{2+}$ adsorption onto $\gamma$ - $\mathrm{Fe}_{2} \mathrm{O}_{3}$ nanoadsorbents. Initial $\mathrm{Pb}^{2+}$ concentration: $50 \mathrm{mg} / \mathrm{L}$. Adsorbent dose: $10 \mathrm{~g} / \mathrm{L}$, shaking rate: $200 \mathrm{rpm}, \mathrm{T}: 22 \pm 2^{\circ} \mathrm{C}$.

in the increase in the adsorption capacity. On the other hand, in a water sample with lower $\mathrm{pH}$, the positively charged sites dominate and this could enhance the repulsion forces existing between the sorbent surface and the $\mathrm{Pb}^{2+}$ ions and therefore decrease the adsorption of $\mathrm{Pb}^{2+}$ ions.

3.4. Effects of Salinity. Increasing $\mathrm{NaCl}$ salinity from $0 \%$ to $3.5 \%$ (the salinity of seawater) had no effects on the removal of $\mathrm{Pb}^{2+}$ by $\gamma-\mathrm{Fe}_{2} \mathrm{O}_{3}$ nanoadsorbents. This suggested that no interaction occurred among $\mathrm{NaCl}, \mathrm{Pb}^{2+}$ and $\gamma-\mathrm{Fe}_{2} \mathrm{O}_{3}$ nanoadsorbents, and the complexation of $\mathrm{Pb}^{2+}$, and $\mathrm{Cl}^{-}$was much weaker than the coordination between $\mathrm{Pb}^{2+}$ and the adsorptive sites on the surfaces of $\gamma-\mathrm{Fe}_{2} \mathrm{O}_{3}$ nanoadsorbents.

\section{Conclusions}

This study showed that the prepared $\gamma-\mathrm{Fe}_{2} \mathrm{O}_{3}$ nanoparticles could be used as an alternate to the conventional adsorbents for the removal of metal ions from wastewater with high removal efficiency within a very short time. The removal of $\mathrm{Pb}^{2+}$, as a typical metal ion commonly present in wastewater, by adsorption onto $\gamma-\mathrm{Fe}_{2} \mathrm{O}_{3}$ nanoparticles was successfully accomplished. Adsorption was very rapid and equilibrium was achieved within $15 \mathrm{~min}$. It also showed that adsorption was highly dependent on the initial concentration of $\mathrm{Pb}^{2+}$ and initial $\mathrm{pH}$ value. Maximum removal efficiency was achieved at $\mathrm{pH} 5.5$ at room temperature. Increasing $\mathrm{NaCl}$ from $0 \%$ to $3.5 \%$ (the salinity of seawater) had no effects on the adsorption of $\mathrm{Pb}^{2+}$ on $\gamma-\mathrm{Fe}_{2} \mathrm{O}_{3}$ nanoparticles. The adsorption isotherms were also determined and were appropriately described by both Langmuir and Freundlich models, with a better fitting to the Langmuir model than the Freundlich model. Therefore, $\gamma$ - $\mathrm{Fe}_{2} \mathrm{O}_{3}$ nanoparticles were recommended as fast, effective, and inexpensive nanoadsorbents for rapid removal and recovery of metal ions from industrial wastewater.

\section{Acknowledgment}

This work was supported by the Ministry of Education Innovation Fund of Singapore (MOE2008-IF-1-010).

\section{References}

[1] F. Fu and Q. Wang, "Removal of heavy metal ions from wastewaters: a review," Journal of Environmental Management, vol. 92, no. 3, pp. 407-418, 2011.

[2] K. C. Kang, S. S. Kim, J. W. Choi, and S. H. Kwon, "Sorption of $\mathrm{Cu}^{2+}$ and $\mathrm{Cd}^{2+}$ onto acid- and base-pretreated granular activated carbon and activated carbon fiber samples," Journal of Industrial and Engineering Chemistry, vol. 14, no. 1, pp. 131135, 2008.

[3] A. Jusoh, L. Su Shiung, N. Ali, and M. J. M. M. Noor, "A simulation study of the removal efficiency of granular activated carbon on cadmium and lead," Desalination, vol. 206, no. 1-3, pp. 9-16, 2007.

[4] Y. Li, F. Liu, B. Xia et al., "Removal of copper from aqueous solution by carbon nanotube/calcium alginate composites," Journal of Hazardous Materials, vol. 177, no. 1-3, pp. 876-880, 2010.

[5] M. I. Kandah and J. L. Meunier, "Removal of nickel ions from water by multi-walled carbon nanotubes," Journal of Hazardous Materials, vol. 146, no. 1-2, pp. 283-288, 2007.

[6] Y. H. Li, Z. Di, J. Ding, D. Wu, Z. Luan, and Y. Zhu, "Adsorption thermodynamic, kinetic and desorption studies of $\mathrm{Pb}^{2+}$ on carbon nanotubes," Water Research, vol. 39, no. 4, pp. 605-609, 2005.

[7] A. Dabrowski, Z. Hubicki, P. Podkocielny, and E. Robens, "Selective removal of the heavy metal ions from waters and industrial wastewaters by ion-exchange method," Chemosphere, vol. 56, no. 2, pp. 91-106, 2004.

[8] Z. Ai, Y. Cheng, L. Zhang, and J. Qiu, "Efficient removal of $\mathrm{Cr}(\mathrm{VI})$ from aqueous solution with $\mathrm{Fe} @ \mathrm{Fe}_{2} \mathrm{O}_{3}$ core-shell nanowires," Environmental Science and Technology, vol. 42, no. 18, pp. 6955-6960, 2008. 
[9] T. Aman, A. A. Kazi, M. U. Sabri, and Q. Bano, "Potato peels as solid waste for the removal of heavy metal copper(II) from waste water/industrial effluent," Colloids and Surfaces B, vol. 63, no. 1, pp. 116-121, 2008.

[10] S. J. Köhler, P. Cubillas, J. D. Rodríguez-Blanco, C. Bauer, and M. Prieto, "Removal of cadmium from wastewaters by aragonite shells and the influence of other divalent cations," Environmental Science and Technology, vol. 41, no. 1, pp. 112118, 2007.

[11] P. Pavasant, R. Apiratikul, V. Sungkhum, P. Suthiparinyanont, S. Wattanachira, and T. F. Marhaba, "Biosorption of $\mathrm{Cu}^{2+}$, $\mathrm{Cd}^{2+}, \mathrm{Pb}^{2+}$, and $\mathrm{Zn}^{2+}$ using dried marine green macroalga Caulerpa lentillifera," Bioresource Technology, vol. 97, no. 18, pp. 2321-2329, 2006.

[12] M. Souiri, I. Gammoudi, H. B. Ouada et al., "Escherichia coli-functionalized magnetic nanobeads as an ultrasensitive biosensor for heavy metals," Procedia Chemistry, vol. 1, no. 1, pp. 1027-1030, 2009.

[13] J. T. Mayo, C. Yavuz, S. Yean et al., "The effect of nanocrystalline magnetite size on arsenic removal," Science and Technology of Advanced Materials, vol. 8, no. 1-2, pp. 71-75, 2007.

[14] C. T. Yavuz, J. T. Mayo, W. W. Yu et al., "Low-field magnetic separation of monodisperse $\mathrm{Fe}_{3} \mathrm{O}_{4}$ nanocrystals," Science, vol. 314, no. 5801, pp. 964-967, 2006.

[15] J. Hu, G. Chen, and I. M. C. Lo, "Removal and recovery of $\mathrm{Cr}(\mathrm{VI})$ from wastewater by maghemite nanoparticles," Water Research, vol. 39, no. 18, pp. 4528-4536, 2005.

[16] A. S. Teja and P. Y. Koh, "Synthesis, properties, and applications of magnetic iron oxide nanoparticles," Progress in Crystal Growth and Characterization of Materials, vol. 55, no. 1-2, pp. 22-45, 2009.

[17] T. Neuberger, B. Schöpf, H. Hofmann, M. Hofmann, and B. Von Rechenberg, "Superparamagnetic nanoparticles for biomedical applications: possibilities and limitations of a new drug delivery system," Journal of Magnetism and Magnetic Materials, vol. 293, no. 1, pp. 483-496, 2005.

[18] V. Sreeja and P. A. Joy, "Microwave-hydrothermal synthesis of $\gamma-\mathrm{Fe}_{2} \mathrm{O}_{3}$ nanoparticles and their magnetic properties," Materials Research Bulletin, vol. 42, no. 8, pp. 1570-1576, 2007.

[19] T. J. Daou, G. Pourroy, S. Bégin-Colin et al., "Hydrothermal synthesis of monodisperse magnetite nanoparticles," Chemistry of Materials, vol. 18, no. 18, pp. 4399-4404, 2006.

[20] K. Simeonidis, S. Mourdikoudis, M. Moulla et al., "Controlled synthesis and phase characterization of Fe-based nanoparticles obtained by thermal decomposition," Journal of Magnetism and Magnetic Materials, vol. 316, no. 2, pp. e1-e4, 2007.

[21] W. Zhou, K. Tang, S. Zeng, and Y. Qi, "Room temperature synthesis of rod-like $\mathrm{FeC}_{2} \mathrm{O}_{4} \cdot{ }_{2} \mathrm{H}_{2} \mathrm{O}$ and its transition to maghemite, magnetite and hematite nanorods through controlled thermal decomposition," Nanotechnology, vol. 19, no. 6, Article ID 065602, 2008.

[22] W. Yu, T. Zhang, J. Zhang, X. Qiao, L. Yang, and Y. Liu, "The synthesis of octahedral nanoparticles of magnetite," Materials Letters, vol. 60, no. 24, pp. 2998-3001, 2006.

[23] I. Nedkov, T. Merodiiska, L. Slavov, R. E. Vandenberghe, Y. Kusano, and J. Takada, "Surface oxidation, size and shape of nano-sized magnetite obtained by co-precipitation," Journal of Magnetism and Magnetic Materials, vol. 300, no. 2, pp. 358367, 2006.

[24] P. D. Cozzoli, E. Snoeck, M. A. Garcia et al., "Colloidal synthesis and characterization of tetrapod-shaped magnetic nanocrystals," Nano Letters, vol. 6, no. 9, pp. 1966-1972, 2006.

[25] A. Uheida, M. Iglesias, C. Fontàs et al., "Sorption of palladium(II), rhodium(III), and platinum(IV) on $\mathrm{Fe}_{3} \mathrm{O}_{4}$ nanoparticles," Journal of Colloid and Interface Science, vol. 301, no. 2, pp. 402-408, 2006.

[26] A. Uheida, G. Salazar-Alvarez, E. Björkman, Z. Yu, and M. Muhammed, " $\mathrm{Fe}_{3} \mathrm{O}_{4}$ and $\gamma-\mathrm{Fe}_{2} \mathrm{O}_{3}$ nanoparticles for the adsorption of $\mathrm{Co}^{2+}$ from aqueous solution," Journal of Colloid and Interface Science, vol. 298, no. 2, pp. 501-507, 2006.

[27] H. Sun, X. Zhang, Q. Niu, Y. Chen, and J. C. Crittenden, "Enhanced accumulation of arsenate in carp in the presence of titanium dioxide nanoparticles," Water, Air, and Soil Pollution, vol. 178, no. 1-4, pp. 245-254, 2007.

[28] P. K. Dutta, A. K. Ray, V. K. Sharma, and F. J. Millero, "Adsorption of arsenate and arsenite on titanium dioxide suspensions," Journal of Colloid and Interface Science, vol. 278, no. 2, pp. 270-275, 2004.

[29] T. K. Naiya, A. K. Bhattacharya, and S. K. Das, "Adsorption of $\mathrm{Pb}$ (II) by sawdust and neem bark from aqueous solutions," Environmental Progress, vol. 27, no. 3, pp. 313-328, 2008.

[30] S. Z. Lee, L. Chang, H. H. Yang, C. M. Chen, and M. C. Liu, "Adsorption characteristics of lead onto soils," Journal of Hazardous Materials, vol. 63, no. 1, pp. 37-49, 1998.

[31] P. Roonasi and A. Holmgren, "An ATR-FTIR study of sulphate sorption on magnetite; rate of adsorption, surface speciation, and effect of calcium ions," Journal of Colloid and Interface Science, vol. 333, no. 1, pp. 27-32, 2009.

[32] S. B. Johnson, G. V. Franks, P. J. Scales, D. V. Boger, and T. W. Healy, "Surface chemistry-rheology relationships in concentrated mineral suspensions," International Journal of Mineral Processing, vol. 58, no. 1-4, pp. 267-304, 2000. 


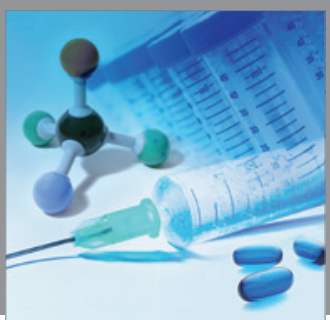

International Journal of

Medicinal Chemistry

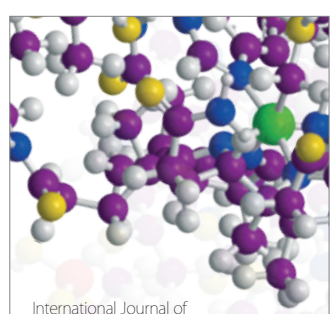

Carbohydrate Chemistry

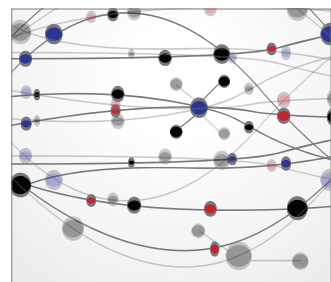

The Scientific World Journal
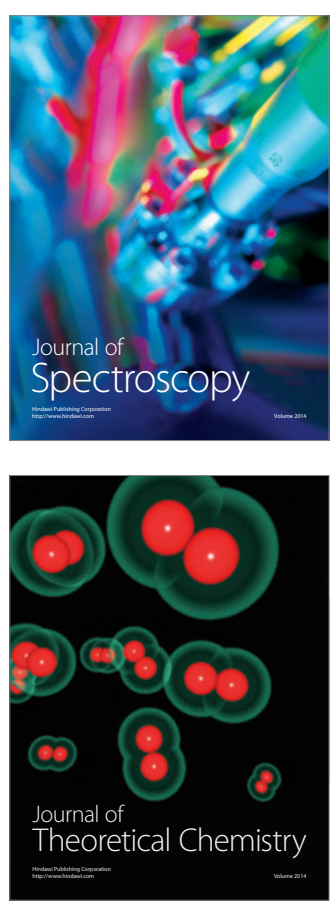
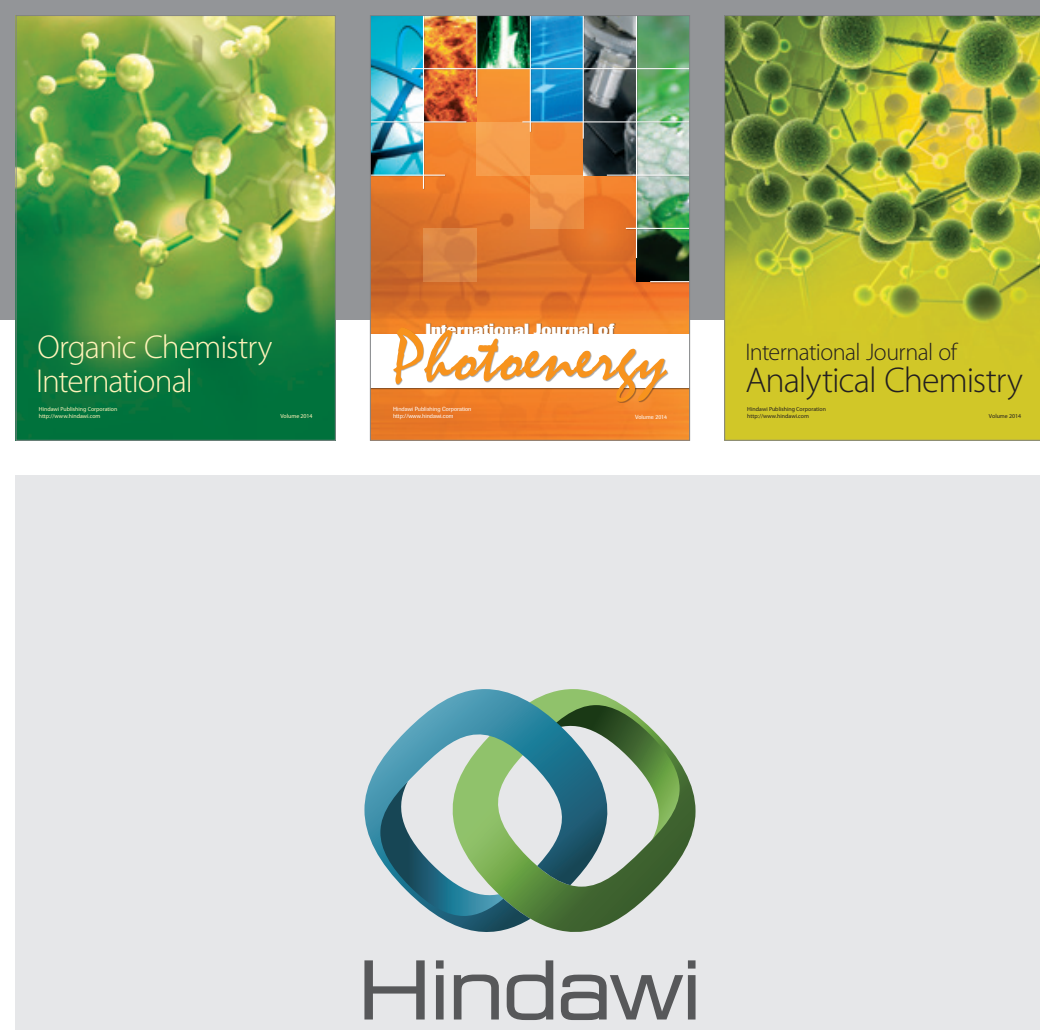

Submit your manuscripts at

http://www.hindawi.com
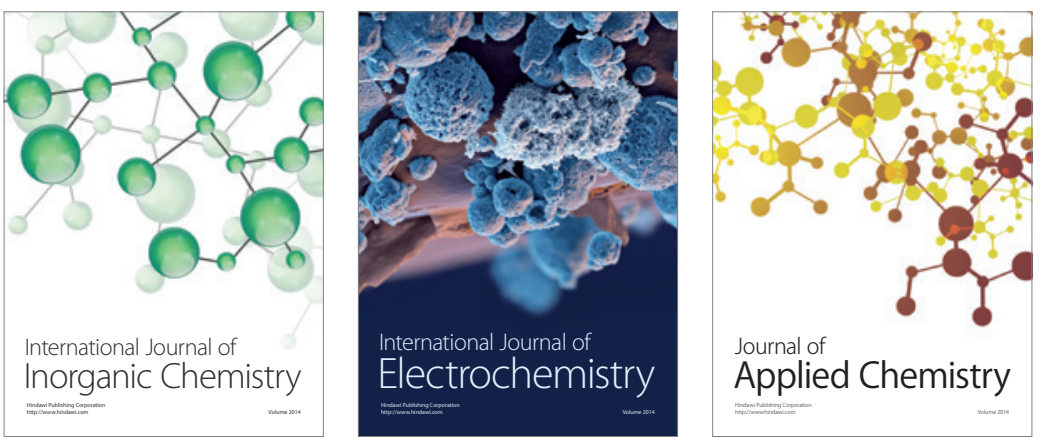

Journal of

Applied Chemistry
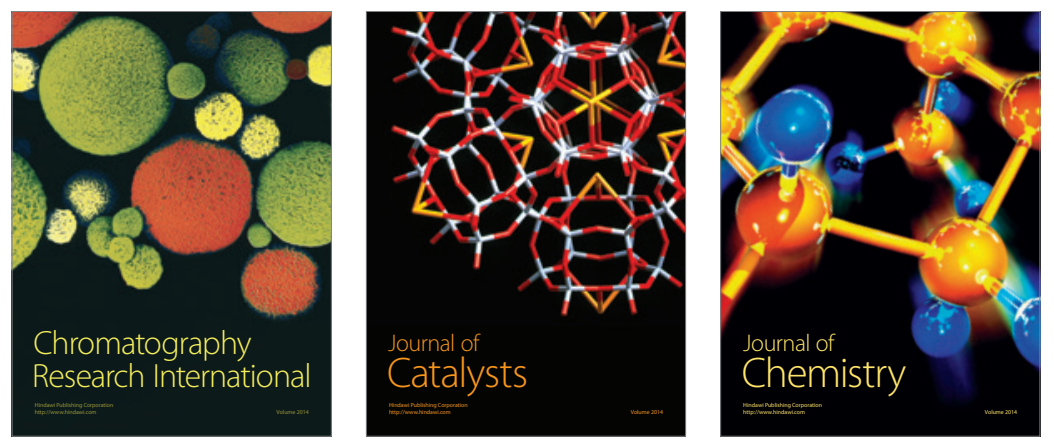
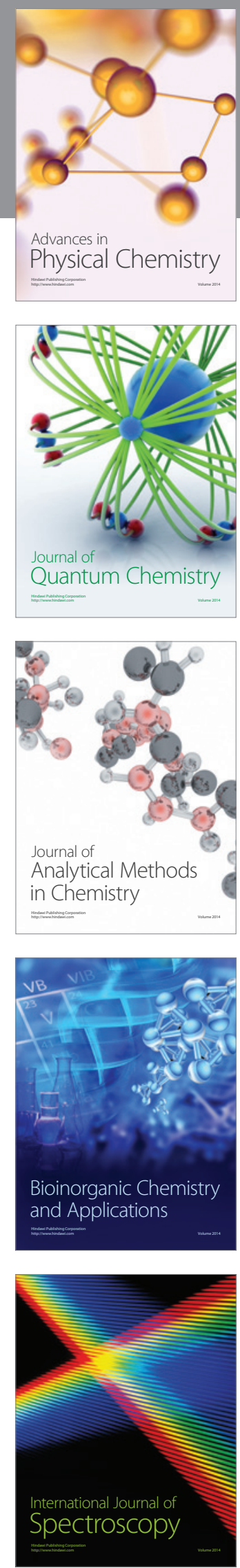